\title{
Absence of a Significant Interaction of Two Common NOS1 and 5-HTT Polymorphisms on Sensorimotor Gating in Humans
}

\author{
Rastislav ROVNÝ ${ }^{1}$, Martin MARKO ${ }^{1}$, Gabriel MINÁRIK ${ }^{2}$, Igor RIEČANSKÝ ${ }^{1,3,4}$ \\ ${ }^{1}$ Department of Behavioural Neuroscience, Institute of Normal and Pathological Physiology, Centre \\ of Experimental Medicine, Slovak Academy of Sciences, Bratislava, Slovak Republic, ${ }^{2}$ Department \\ of Molecular Biology, Faculty of Natural Sciences, Comenius University in Bratislava, Bratislava, \\ Slovak Republic, ${ }^{3}$ Social, Cognitive and Affective Neuroscience Unit, Department of Cognition, \\ Emotion, and Methods in Psychology, Faculty of Psychology, University of Vienna, Vienna, \\ Austria, ${ }^{4}$ Department of Psychiatry, Faculty of Medicine, Slovak Medical University, Bratislava, \\ Slovak Republic
}

Received April 15, 2021

Accepted October 11, 2021

\begin{abstract}
Summary
The neurotransmitter serotonin has been critically implicated in the pathogenesis of several mental disorders. The serotonin transporter (5-HTT) is a key regulator of serotonergic neurotransmission and its genetic variability is associated with increased risk of psychopathology. One well known polymorphic locus in the $5-H T T$ gene affecting its expression is a tandem repeat in the promoter region (5-HTTLPR). It has been reported that $5-\mathrm{HTT}$ is functionally coupled with the neuronal nitric oxide synthase (NOS1 or nNOS), an enzyme catalyzing the production of nitric oxide (NO). We have previously demonstrated that a tandem repeat polymorphism in the promoter of NOS1 exon $1 \mathrm{f}$ (Ex1f-VNTR) is associated with sensorimotor gating, a marker of inhibitory processing and a well-established endophenotype of several neuropsychiatric disorders. Here we investigated the combined genetic effects of NOS1 Ex1f-VNTR and 5-HTTLPR on sensorimotor gating, measured by prepulse inhibition (PPI) of the acoustic startle reflex, in 164 healthy adults. We found no evidence for the interaction between NOS1 Ex1f-VNTR and 5-HTTLPR on PPI. PPI was associated with NOS1 Ex1f-VNTR, but not 5-HTTLPR. Our data suggest that while NOS1 plays a role in sensorimotor gating, the nitrergic pathway of gating regulation does not involve the action of 5-HTT.
\end{abstract}

\section{Key words}

Prepulse inhibition • Serotonin • Serotonin transporter • Nitric oxide • Endophenotype

\section{Corresponding author}

I. Riečanský, Institute of Normal and Pathological Physiology, Centre of Experimental Medicine, Slovak Academy of Sciences, Sienkiewiczova 1, 81371 Bratislava, Slovak Republic. E-mail: igor.riecansky@savba.sk

\section{Introduction}

Sensorimotor gating is an automatic neural process that enables humans and animals to suppress non-salient sensory input at the early stage of information processing. This process is thought to protect the brain from sensory overload and facilitate the efficient engagement of limited attentional resources (Light and Braff 1999). Sensorimotor gating is routinely examined by measuring prepulse inhibition (PPI) of the acoustic startle reflex. PPI is a reduction in the magnitude of the startle response to a loud auditory stimulus (pulse) when a weak non-startling stimulus (prepulse) is presented shortly before the loud stimulus (typically 30-500 ms). PPI deficit is one of the most reliable neurophysiological alterations associated with schizophrenia but also several other neuropsychiatric conditions, including obsessivecompulsive disorder (OCD), panic disorder, Tourette syndrome, or Huntington's disease (for reviews, see e.g. Swerdlow and Light 2018 and Kohl et al. 2013). Abnormalities of sensorimotor gating are present not only in psychiatric patients but also in their unaffected 
relatives, i.e. individuals with increased genetic risk for the disorders (Li et al. 2020). Hence, PPI is considered as a biomarker (endophenotype or intermediate phenotype) of these disorders and its heritability has been estimated to $29-58 \%$ (Rovný et al. 2020).

There is increasing evidence for a role of nitric oxide (NO) in neuropsychiatric disorders (for a recent review, see e.g. Tripathi et al. 2020). Research on the involvement of NO in the regulation of PPI may thus contribute to a better understanding of the etiopathogenesis of mental illness. We have recently demonstrated that variation of the gene encoding the neuronal nitric oxide synthase (NOS1, also referred to as $n N O S$ ) is associated with PPI in healthy humans (Rovný et al. 2018). In particular, PPI was weaker in carriers of a short allele of a VNTR (variable number of tandem repeats) polymorphism in the promoter region of exon $1 \mathrm{f}$ (Ex1f-VNTR). This allele is associated with lower NOS1 transcription and increased risk of psychopathology (for a review, see Freudenberg et al. 2015). In the present study, we have made a step further to explore a potential factor or mechanism moderating the effect of NOS1 genotype on PPI and focused on the serotonin transporter (5-HTT), which is responsible for the reuptake of the neurotransmitter serotonin (5-hydroxytryptamine, 5-HT) into presynaptic neurons. It has been namely shown that NOS1 interacts with 5-HTT in two ways: first, NO (produced by NOS1) modulates the activity of 5-HTT through a cyclic guanosine monophosphate/protein kinase G-dependent mechanism; and second, via direct proteinprotein interaction, NOS1 inhibits the trafficking of 5-HTT to the plasma membrane (Chanrion et al. 2007, for reviews, see Garthwaite 2007 and Bermingham and Blakely 2016). Thus, the activation of the nitrergic pathway may increase the concentration of 5-HT in the synaptic cleft through inhibition of 5-HTT action. Importantly, it has been demonstrated that mice lacking the Nos1 gene show decreased 5-HT turnover as well as profound deficits in impulse control (Chiavegatto et al. 2001).

Several lines of evidence highlight the relevance of serotonergic neurotransmission, including 5-HTT, in the pathophysiology and treatment of mental disorders (for a review, see Spies et al. 2015). Moreover, particularly relevant for our study, genetic variants in 5-HTT and other proteins involved in serotonergic neurotransmission have been linked not only with impaired functioning, but also normal variability in mental functions and behavior (for a review, see Serretti et al. 2006). By far the most extensively studied polymorphism in the 5-HTT gene (SLC6A4) is a tandem repeat in the promoter region, the so-called serotonintransporter-linked polymorphic region (5-HTTLPR). The length of 5-HTTLPR affects the level of expression of SLC6A4 (Lesch et al. 1996) and has been linked with an increased risk of psychopathology, including affective and anxiety disorders, OCD or Tourette syndrome (Anguelova et al. 2003, Gressier et al. 2013, Moya et al. 2013, Taylor 2013). Considering the functional link between 5-HTT and NOS1, as well as the role of complex genetic architecture of mental functions and their disorders, we expected the possibility that the genotype of 5-HTTLPR might moderate the effect of NOS1 Ex1f-VNTR on PPI in humans.

\section{Methods}

\section{Study participants}

In the current study, we extended a previously described cohort of 96 healthy adults (Rovný et al. 2018) by including additional 68 individuals, resulting in a total sample of 164 subjects (113 males, mean age $\pm S D=23.6 \pm 3.2 \quad$ years, 54 smokers). Study participants were recruited via advertisement from general population in Bratislava, Slovakia. Study inclusion/exclusion criteria have been reported previously in detail (Rovný et al. 2018). Only healthy subjects with no personal and family history of mental disorders in first-degree relatives, no current medication, no substance abuse (except tobacco) and normal hearing ability were included in this study. In total 57 of 221 subjects were excluded from the study participation. Three subjects were excluded due to family history of severe mental illness among first-degree relatives, 6 subjects had a positive toxicology screen, 15 subjects were startle non-responders, 2 subjects had severe neurological or metabolic disease and 30 subjects were excluded because their genotype could not be assessed. One subject with extreme values of PPI (values deviating more than three times the interquartile range from the upper or lower quartile) was excluded from the statistical analysis. The sample size was estimated based on previous research (e.g. Bräuer et al. 2009) and provided enough statistical power to detect effect sizes equal to or larger than $\eta_{p}^{2}=$ $0.07\left(\alpha=0.05,1-\beta=0.80, \mathrm{G}^{*}\right.$ Power (Faul et al. 2007). Effect sizes of a comparable magnitude were reported in previous genetic studies of PPI (e.g. Quednow et al. 2011). 


\section{Procedures}

The experimental procedures were identical to those described in our previous paper (Rovný et al. 2018). In brief, upon arrival to the lab all participants got information about the procedures and gave their written informed consent. Thereafter, participants were interviewed to obtain information on medical history, health status and use of psychoactive substances. Subsequently, buccal mucosa samples were collected and urine multi-drug toxicology and cotinine tests were carried out. Before the acoustic startle response assessment, all participants underwent a screening test of hearing to verify that their hearing ability is within the normal range. The entire session lasted approximately two hours. Participants received financial reward for study participation. The study was conducted in accordance with the ethical principles of the Declaration of Helsinki and approved by the institutional review board (approval number EK/2/16).

\section{Startle response measurement}

Startle response was measured as described in our previous work (Rovný et al. 2018). The eye-blink component of the acoustic startle reflex was measured by recording electromyogram (EMG) of the orbicularis oculi muscles using surface electrodes. Startle was elicited by white noise bursts administered binaurally through headphones. The auditory stimulation comprised pulse alone trials (PA, $40 \mathrm{~ms}$ burst of white noise at $105 \mathrm{~dB}$ ), prepulse-pulse trials (PP) in which pulse was preceded 30,60 or $120 \mathrm{~ms}$ by a prepulse (20 ms burst of white noise at $75 \mathrm{~dB}$ ). White noise of $55 \mathrm{~dB}$ was continuously presented in the background throughout the session. The stimulation paradigm involved 69 trials, which were divided into three blocks. The first and the third block contained only PA trials (5 and 4, respectively). The second block involved 10 PA trials and 10 PP trials for each PP interval presented in random order. The stimuli were separated by a random inter-trial interval of 10-20 s. PPI at PP intervals of 30,60 and $120 \mathrm{~ms}$ (hereafter denoted as PPI30, PPI60 and PPI120) was calculated as $(1-\mathrm{mPP} / \mathrm{mPA}) \times 100 \%$, where $\mathrm{mPP}$ and $\mathrm{mPA}$ denote mean startle amplitude in PP and PA trials respectively. Baseline startle reactivity was assessed as the mean startle amplitude in the first block and was used as a covariate in the statistical tests of PPI (Csomor et al. 2008).

\section{Genotyping}

Genomic DNA for genotyping was extracted from buccal swabs of participants using $300 \mu \mathrm{l}$ of $5 \%$ CHELEX (CHELEX 100 Resin, Biorad, USA) and incubated at $56^{\circ} \mathrm{C}$ for $30 \mathrm{~min}$ and at $100^{\circ} \mathrm{C}$ for $10 \mathrm{~min}$. During the incubation, samples were repeatedly vortexed and then centrifuged $3 \mathrm{~min}$ at $12000 \mathrm{~g}$. For specific DNA region amplification, universal PCR mastermix containing $1 \times$ PCR mastermix $(5 \times$ HOT FIREPOL Blend Mastermix (Solis BioDyne, Tartu, Estonia)), 5 pmol FAM-labelled assay specific primers (NOS1 Ex1f-VNTR: 5'-CCCTGCGTGGCTACTACTACATT-3' and 5'-CTGGGCTCCAAAGCATACAT-3'; 5-HTTLPR: 5'-GGCGTTGCCGCTCTGAATGC-3' and 5'-GAGGGACTGAGCTGGACAACCAC-3'; Heils et al. 2002, Hoogman et al. 2011), $5 \mu \mathrm{l}$ DNA solution and nuclease free water to final volume $20 \mu \mathrm{l}$ was used. The following PCR program was used: initial denaturation step at $95{ }^{\circ} \mathrm{C}$ for $5 \mathrm{~min}$, followed by 30 cycles each consisting of denaturation step at $94{ }^{\circ} \mathrm{C}$ for $45 \mathrm{~s}$, annealing step at $60{ }^{\circ} \mathrm{C}$ for $45 \mathrm{~s}$, polymerization step at $72{ }^{\circ} \mathrm{C}$ for $45 \mathrm{~s}$ and then final polymerization step at $72{ }^{\circ} \mathrm{C}$ for $10 \mathrm{~min}$. For detection of the genotype of the VNTR polymorphism, samples were mixed with solution of HiDi Formamide $(8.5 \mu \mathrm{l}$; Life Technologies, USA) and LIZ 500 Size Standard ( $0.5 \mu$; Life Technologies, USA) in ratio $1: 9$, denatured at $95^{\circ} \mathrm{C}$ for $5 \mathrm{~min}$ and genotyped using fragment analysis on ABI Prism 3130xl Genetic Analyzer and software GeneMapper v3.5 (Life Technologies, USA). Based on earlier studies (Nakamura et al. 2000, Freudenberg et al. 2015), alleles were classified as short (NOS1 Ex1f-VNTR: 19-27, 5-HTTLPR: 14 repeats, respectively) or long (NOS1 Ex1f-VNTR: 28-36, 5-HTTLPR: 16 repeats, respectively).

\section{Statistical analysis}

Data were analyzed using SPSS 22 (SPSS Inc., Chicago, IL USA) and JASP v0.13.1 software (JASP Team 2020). Prior to the statistical analyses all outcome variables were inspected for distributional properties and extreme values. Outliers identified by the standard interquartile range rule of 1.5 were treated using a one-sided winsorization at the $2.5^{\text {th }}$ percentile for variables PPI30, PPI60 and PPI120 (Wilcox 2012). Categorical variables were described by absolute and relative frequencies, and continuous variables by means and standard deviations, respectively. Pearson productmoment correlation coefficients were computed between age and the startle measures (BSR, PPI30, PPI60, and 
PPI120). The differences in relative frequencies in sex and smoking status were tested by $\chi^{2}$ tests. The independent-samples Student's $t$-tests were used to test the differences in mean startle measures for sex, smoking status and genotypes (NOS1 Ex1f-VNTR and 5-HTTLPR). The Student's $t$-tests with Welch's approximation of degrees of freedom were used in case the assumption of equality of variances was violated. Pairwise linkage disequilibrium (LD) between NOS1 Ex1f-VNTR and 5-HTTLPR polymorphisms was estimated using Haploview version 4.2 (Barrett et al. 2005). The normalized $D^{\prime}$ statistic was used to calculate LD. The $\chi^{2}$ goodness-of-fit tests were used to determine whether the genotype frequencies of NOS1 Ex1f-VNTR and 5-HTTLPR polymorphisms met the Hardy-Weinberg equilibrium. The differences between the groups defined by the presence of NOS1 Ex1f-VNTR and 5-HTTLPR risk alleles were tested by $\chi^{2}$ tests or independentsamples $t$-tests. The effects of genotype on PPI were assessed by a $2 \times 2 \times 3$ three-way repeated-measures analysis of covariance (ANCOVA) with two fixed between-subjects factors (NOS1 Ex1f-VNTR and 5-HTTLPR genotype, 2 levels each), one fixed within-subjects factor (prepulse-pulse interval, 3 levels) and BSR as a continuous fixed covariate. Post hoc comparisons were performed with Tukey's honestly significant difference post hoc tests. Age, sex and tobacco smoking status were included as fixed effects in next ANCOVA models to explore their effects on the PPI measures (Swerdlow et al. 1993, Kumari et al. 1996, Ludewig et al. 2003). All null hypotheses were tested against two-sided alternative hypotheses at a significance level $\alpha=0.05$. Next, a Bayesian approach was implemented to further investigate the genetic interaction. A Bayesian $2 \times 2 \times 3$ three-way repeated-measures ANCOVA was conducted in JASP. The default JASP priors were used ( $\mathrm{r}$ scale prior width of 0.5 for fixed effects and 0.354 for covariates). A classification scheme proposed by Lee and Wagenmakers (2013) was employed for interpreting the magnitude of Bayes factors. Accordingly, $\mathrm{BF}_{10}$ more than 3 and less than $1 / 3$ were classified as indicative of more than anecdotal evidence in favor of the $\mathrm{H} 1$ and $\mathrm{H} 0$, respectively.

\section{Results}

Genotype frequencies for the NOS1 Ex1f-VNTR and 5-HTTLPR polymorphisms (Table 1) were distributed according to Hardy-Weinberg equilibrium (NOS1 Ex1f-VNTR: $\quad \chi^{2}(1)=0.005, \quad p=0.94 ; \quad 5$-HTTLPR $\left.\chi^{2}(1)=0.034, p=0.85\right)$. Linkage disequilibrium between the two polymorphisms was weak $\left(D^{\prime}=0.014\right)$. To ensure an adequate size of genotype groups for statistical analysis, homozygotes and heterozygotes for the rare alleles (short for both loci) were classified as minor allele carriers (Table 1). These genotype groups did not differ significantly in sex, age, smoking status, or baseline startle reactivity $\left(\chi^{2}\right.$ or $t$-tests as appropriate, all $p$-values $\left.>0.05\right)$.

To evaluate the experimental effects, a repeatedmeasures analysis of covariance (RM-ANCOVA) with baseline startle magnitude as a covariate was calculated (Table 2). The main effect of prepulse-pulse (PP) interval was significant $(p=0.002)$, in agreement with the well known feature of PPI to increase with increasing PP interval duration (mean values: PPI $30=65.1 \%$, PPI $60=75.0 \%, \quad$ PPI $120=76.2 \%$ ). Furthermore, a significant effect of NOS1 Ex1f-VNTR genotype was revealed $(p=0.038)$. Individuals carrying the short (risk) allele of Ex1f-VNTR had significantly weaker PPI compared with homozygotes for the long allele of Exlf-VNTR (Fig. 1A). 5-HTTLPR genotype showed no significant main effect or interaction with NOS1 Ex1f-VNTR genotype (Fig. 1B, C). These results did not change when age, sex or smoking status were included as additional covariates into the model. Next, a Bayesian RM-ANCOVA was calculated to examine the plausibility of the genetic interaction between NOS1 Ex1f-VNTR and 5-HTTLPR. The estimated Bayes factor $\left(B F_{0 I}=3.25\right)$ indicates that the likelihood of the observed PPI data is more than three times higher under the assumption of absence, rather than presence, of the interaction between NOS1 Ex1f-VNTR and 5-HTTLPR.

Table 1. Allelic distribution of the investigated NOS1 and 5-HTT polymorphisms.

\begin{tabular}{lcccc}
\hline & & \multicolumn{2}{c}{ Genotype } & SS \\
Polymorphism & LL & LS & S+ \\
\hline NOS1 Ex1f-VNTR & $44(26.8 \%)$ & $84(51.2 \%)$ & $36(22.0 \%)$ & $120(73.2 \%)$ \\
$5-H T T L P R$ & $67(40.9 \%)$ & $73(44.5 \%)$ & $24(14.6 \%)$ & $97(59.1 \%)$ \\
\hline
\end{tabular}

L: long allele; S: short allele, S+: carriers of short allele (LS+SS). 


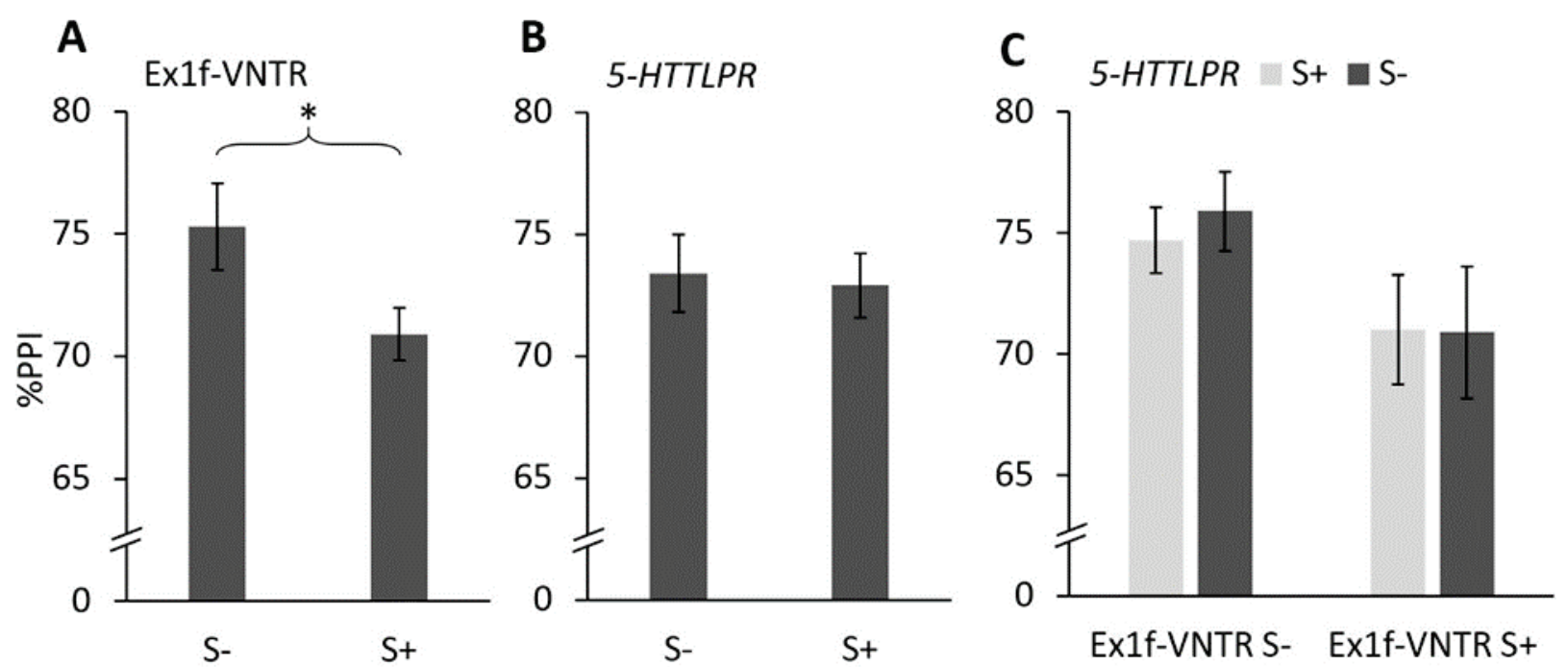

Fig. 1. Prepulse inhibition (estimated means across three prepulse-pulse intervals 30,60, and $120 \mathrm{~ms}$, adjusted for baseline startle magnitude) by genotype of (A) NOS1 Ex1f-VNTR, (B) 5-HTTLPR and (C) combined genotype of Ex1f-VNTR and 5-HTTLPR. Error bars represent \pm SEM. $* p<0.05$.

Table 2. Repeated-measures ANCOVA testing the effects of NOS1 Ex1f-VNTR and 5-HTTLPR on mean PPI with baseline startle response (BSR) as a covariate.

\begin{tabular}{lccc}
\hline Effect & $\mathbf{F}_{(\mathbf{1}, \mathbf{1 5 9})}$ & $\boldsymbol{p}$ & $\boldsymbol{\eta}_{\boldsymbol{p}}^{\mathbf{2}}$ \\
\hline PP interval & 10.27 & 0.002 & 0.043 \\
BSR & 40.95 & $<0.001$ & 0.205 \\
NOS1 Ex1f-VNTR & 4.40 & 0.038 & 0.027 \\
5-HTTLPR & 0.07 & 0.787 & 0.000 \\
PP interval * NOS1 Ex1f-VNTR & 0.00 & 0.960 & 0.000 \\
PP interval * 5-HTTLPR & 0.02 & 0.902 & 0.000 \\
NOS1 Ex1f-VNTR * 5-HTTLPR & 0.10 & 0.759 & 0.001 \\
PP interval * NOS1 Ex1f-VNTR * 5-HTTLPR & 0.04 & 0.834 & 0.000 \\
\hline
\end{tabular}

\section{Discussion}

Numerous studies have linked variability of NOS1 and 5-HTT genes with human behavioral functions and their disturbance manifested in several neuropsychiatric disorders (Serretti et al. 2006, Freudenberg et al. 2015, Gatt et al. 2015, Topaloglu et al. 2017). We have previously demonstrated that NOS1 Ex1f-VNTR polymorphism affects the efficiency of sensorimotor gating, impaired in many of these pathological conditions (Rovný et al. 2018). Given the physiological coupling between NOS1 and 5-HTT (Garthwaite 2007, Bermingham and Blakely 2016), we examined whether common functional genetic variants NOS1 Ex1f-VNTR and 5-HTTLPR, jointly affect sensorimotor gating. We found, however, moderate evidence against the interaction between these polymorphisms on PPI.

In agreement with our previous work (Rovný et al. 2018), the genotype of NOS1 Ex1f-VNTR had a significant impact on PPI so that the carriers of short (risk) allele exhibited less efficient inhibition. Although this finding cannot be interpreted as an independent replication due to partial overlap between the samples, it provides cumulative evidence for the role of $\mathrm{NO}$ in the regulation of sensorimotor gating.

It also fits with our finding in rats, showing that PPI deficits are accompanied by altered NOS1 expression in the brain of animals reared in social isolation after weaning, used as a rodent model of schizophrenia pathology (Chmelova et al. 2019, Vrankova et al. 2021). Since the effect of NOS1 Ex1f-VNTR was not significantly moderated by the genotype of 5-HTTLPR, the nitrergic mechanisms of gating regulation seem not to 
depend on 5-HTT. Furthermore, a simple effect of 5-HTTLPR genotype on PPI was also insignificant. This indicates that the contribution of 5-HTT to psychopathology may not involve a disruption of gating efficiency, which is in line with the fact that a direct association of 5-HTTLPR with PPI has not been reliably documented in previous genetic studies in humans (Rovný et al. 2020). However, we must emphasize that our finding is not in conflict with the abundant evidence for the role of serotonergic mechanisms in gating. For instance, depletion of 5-HT disrupts PPI (Mann et al. 2008), while an opposite effect results from an excessive release of 5-HT, such as following the administration of MDMA (3,4-methylene-dioxymethamphetamine) (Liechti et al. 2001). Human genetic studies of PPI have identified a reliable association with HTR2A gene encoding the 5-HT2A receptor, which has been mostly considered from the perspective of its role in schizophrenia (Baou et al. 2016, Quednow et al. 2020, Rovný et al. 2020). In particular, hallucinogens (such as psilocybin or LSD), which act as agonists at 5-HT2A receptor, disrupt PPI and the blockade of 5-HT2A receptor prevents this effect to occur (Quednow et al. 2012, Halberstadt and Nichols 2020). Nevertheless, 5-HT2A receptor function has also been linked with other disorders associated with gating deficit, such as OCD (Derksen et al. 2020). Moreover, signaling via other types of 5-HT receptors has also been implicated in gating (Sipes and Geyer 1994). For instance, it has been reported that availability of 5-HT1B receptors in the basal ganglia and thalamus positively correlated with PPI in healthy humans while such a relationship was absent in OCD patients (Pittenger et al. 2016). Our data thus suggest that other molecules involved in serotonergic neurotransmission, rather than 5-HTT, may be more probable candidates of nitrergic regulations playing a role in sensorimotor gating. In particular, 5-HT1A and 5-HT2C receptors, which mediate the inhibitory action of 5-HT on NO signaling, may represent promising candidates for future studies (Maura et al. 2000, Raymond et al. 2001).

To conclude, our data suggest that while NOS1 plays a role in sensorimotor gating, the nitrergic pathway of gating regulation does not involve the action of 5 HTT. Although these findings cannot be yet directly translated into clinical practice, they expand our knowledge of the genetic basis of gating, an important psychiatric endophenotype. Such knowledge is necessary to decompose the complex etiopathogenetic architecture of mental disorders and may provide new outlooks for their treatments in the future. Since both nitrergic and serotonergic signaling are importantly involved in many neuropsychiatric disorders, further research on the interactions of these pathways and their roles in the pathogenesis of psychopathological symptoms is warranted.

\section{Conflict of Interest}

There is no conflict of interest.

\section{Acknowledgements}

This work was supported by the Scientific Grant Agency of the Ministry of Education, Science, Research and Sport of the Slovak Republic (grant numbers VEGA 2/0056/16, VEGA 2/0039/17, and VEGA 2/0170/19) and the Slovak Research and Development Agency (grant number APVV-14-0840). We thank Dominika Besterciová and Annamária Róžová for help with data collection and Laura Blažeková for technical assistance with DNA extraction and genotyping.

\section{References}

ANGUELOVA M, BENKELFAT C, TURECKI G: A systematic review of association studies investigating genes coding for serotonin receptors and the serotonin transporter: I. Affective disorders. Mol Psychiatry 8: 574-591, 2003. https://doi.org/10.1038/sj.mp.4001328

BAOU M, BOUMBA VA, PETRIKIS P, RALLIS G, VOUGIOUKLAKIS T, MAVREAS V: A review of genetic alterations in the serotonin pathway and their correlation with psychotic diseases and response to atypical antipsychotics. Schizophr Res 170: 18-29, 2016. https://doi.org/10.1016/j.schres.2015.11.003

BARRETT JC, FRY B, MALLER J, DALY MJ: Haploview: Analysis and visualization of LD and haplotype maps. Bioinformatics 21: 263-265, 2005. https://doi.org/10.1093/bioinformatics/bth457

BERMINGHAM DP, BLAKELY RD: Kinase-dependent regulation of monoamine neurotransmitter transporters. Pharmacol Rev 68: 888-953, 2016. https://doi.org/10.1124/pr.115.012260 
BRÄUER D, STROBEL A, HENSCH T, DIERS K, LESCH K-P, BROCKE B: Genetic variation of serotonin receptor function affects prepulse inhibition of the startle. J Neural Transm 116: 607-613, 2009. https://doi.org/10.1007/s00702-009-0222-0

CHANRION B, MANNOURY LA COUR C, BERTASO F, LERNER-NATOLI M, FREISSMUTH M, MILLAN MJ, BOCKAERT J, MARIN P: Physical interaction between the serotonin transporter and neuronal nitric oxide synthase underlies reciprocal modulation of their activity. Proc Natl Acad Sci U S A 104: 8119-8124, 2007. https://doi.org/10.1073/pnas.0610964104

CHIAVEGATTO S: Brain serotonin dysfunction accounts for aggression in male mice lacking neuronal nitric oxide synthase. Proc Natl Acad Sci U S A 98: 1277-1281, 2001. https://doi.org/10.1073/pnas.031487198

CHMELOVA M, BALAGOVA L, MARKO M, VRANKOVA S, CEBOVA M, JEZOVA D, RIECANSKY I, HLAVACOVA N: Behavioral alterations induced by post-weaning isolation rearing of rats are accompanied by reduced VGF/BDNF/TrkB signaling in the hippocampus. Neurochem Int 129: 104473, 2019. https://doi.org/10.1016/j.neuint.2019.104473

CSOMOR PA, YEE BK, VOLLENWEIDER FX, FELDON J, NICOLET T, QUEDNOW BB: On the influence of baseline startle reactivity on the indexation of prepulse inhibition. Behav Neurosci 122: 885-900, 2008. https://doi.org/10.1037/0735-7044.122.4.885

DERKSEN M, FEENSTRA M, WILLUHN I, DENYS D: The serotonergic system in obsessive-compulsive disorder. In: Handbook of Behavioral Neuroscience. MÜLLER CP, JACOBS BL (eds), Elsevier B.V., Amsterdam, 2020, pp 865-891. https://doi.org/10.1016/B978-0-444-64125-0.00044-X

FAUL F, ERDFELDER E, LANG A-G, BUCHNER A: G*Power 3: A flexible statistical power analysis program for the social, behavioral, and biomedical sciences. Behav Res Methods 39: 175-191, 2007. https://doi.org/10.3758/BF03193146

FREUDENBERG F, ALTTOA A, REIF A: Neuronal nitric oxide synthase (NOS1) and its adaptor, NOS1AP, as a genetic risk factors for psychiatric disorders. Genes Brain Behav 14: 46-63, 2015. https://doi.org/10.1111/gbb.12193

GARTHWAITE J: Neuronal nitric oxide synthase and the serotonin transporter get harmonious. Proc Natl Acad Sci U S A 104: 7739-7740, 2007. https://doi.org/10.1073/pnas.0702508104

GATT JM, BURTON KLO, WILLIAMS LM, SCHOFIELD PR: Specific and common genes implicated across major mental disorders: A review of meta-analysis studies. J Psychiatr Res 60: 1-13, 2015. https://doi.org/10.1016/j.jpsychires.2014.09.014

GRESSIER F, CALATI R, BALESTRI M, MARSANO A, ALBERTI S, ANTYPA N, SERRETTI A: The 5-HTTLPR polymorphism and posttraumatic stress disorder: A meta-analysis. J Trauma Stress 26: 645-653, 2013. https://doi.org/10.1002/jts.21855

HALBERSTADT AL, NICHOLS DE: Serotonin and serotonin receptors in hallucinogen action. In: Handbook of Behavioral Neuroscience. MÜLLER CP, CUNNINGHAM KA (eds), Elsevier B.V., Amsterdam, 2020, pp 843-863. https://doi.org/10.1016/B978-0-444-64125-0.00043-8

HEILS A, TEUFEL A, PETRI S, STÖBER G, RIEDERER P, BENGEL D, LESCH KP: Allelic variation of human serotonin transporter gene expression. J Neurochem 66: 2621-2624, 2002. https://doi.org/10.1046/j.1471$\underline{4159.1996 .66062621 . x}$

HOOGMAN M, AARTS E, ZWIERS M, SLAATS-WILLEMSE D, NABER M, ONNINK M, COOLS R, KAN C, BUITELAAR J, FRANKE B: Nitric oxide synthase genotype modulation of impulsivity and ventral striatal activity in adult ADHD patients and healthy comparison subjects. Am J Psychiatry 168: 1099-1106, 2011. https://doi.org/10.1176/appi.ajp.2011.10101446

JASP Team: JASP (Version 0.14)[Computer software]. 2020.

KISS J: Nitric oxide: A novel link between synaptic and nonsynaptic transmission. Trends Neurosci 24: 211-215, 2001. https://doi.org/10.1016/S0166-2236(00)01745-8

KOHL S, HEEKEREN K, KLOSTERKÖTTER J, KUHN J: Prepulse inhibition in psychiatric disorders - Apart from schizophrenia. J Psychiatr Res 47: 445-452, 2013. https://doi.org/10.1016/j.jpsychires.2012.11.018 
KUMARI V, CHECKLEY SA, GRAY JA: Effect of cigarette smoking on prepulse inhibition of the acoustic startle reflex in healthy male smokers. Psychopharmacology (Berl) 128: 54-60, 1996. https://doi.org/10.1007/s002130050109

LEE MD, WAGENMAKERS E-J: Bayesian model comparison. In: Bayesian Cognitive Modeling: A Practical Course. Cambridge University Press, Cambridge, 2013, pp 101-117. https://doi.org/10.1017/CBO9781139087759

LESCH KP, BENGEL D, HEILS A, SABOL SZ, GREENBERG BD, PETRI S, BENJAMIN J, MÜLLER CR, HAMER DH, MURPHY DL: Association of anxiety-related traits with a polymorphism in the serotonin transporter gene regulatory region. Science 274: 1996. https://doi.org/10.1126/science.274.5292.1527

LI W, MAO Z, BO Q, SUN Y, WANG Z, WANG C: Prepulse inhibition in first-degree relatives of schizophrenia patients: A systematic review. Early Interv Psychiatry 15: 652-661, 2021. https://doi.org/10.1111/eip.13003

LIECHTI ME, GEYER MA, HELL D, VOLLENWEIDER FX: Effects of MDMA (ecstasy) on prepulse inhibition and habituation of startle in humans after pretreatment with citalopram, haloperidol, or ketanserin. Neuropsychopharmacology 24: 240-252, 2001. https://doi.org/10.1016/S0893-133X(00)00199-8

LIGHT GA, BRAFF DL: Human and animal studies of schizophrenia-related gating deficits. Curr Psychiatry Rep 1: 31-40, 1999. https://doi.org/10.1007/s11920-999-0008-y

LUDEWIG K, LUDEWIG S, SEITZ A, OBRIST M, GEYER MA, VOLLENWEIDER FX: The acoustic startle reflex and its modulation: Effects of age and gender in humans. Biol Psychol 63: 311-323, 2003. https://doi.org/10.1016/S0301-0511(03)00074-7

MANN C, CROFT RJ, SCHOLES KE, DUNNE A, O'NEILL BV, LEUNG S, COPOLOV D, PHAN KL, NATHAN PJ: Differential effects of acute serotonin and dopamine depletion on prepulse inhibition and P50 suppression measures of sensorimotor and sensory gating in humans. Neuropsychopharmacology 33: 1653-1666, 2008. https://doi.org/10.1038/sj.npp.1301556

MAURA G, MARCOLI M, PEPICELLI O, ROSU C, VIOLA C, RAITERI M: Serotonin inhibition of the NMDA receptor/nitric oxide/cyclic GMP pathway in human neocortex slices: Involvement of 5-HT(2C) and 5-HT(1A) receptors. Br J Pharmacol 130: 1853-1858, 2000. https://doi.org/10.1038/sj.bjp.0703510

MOYA PR, WENDLAND JR, RUBENSTEIN LM, TIMPANO KR, HEIMAN GA, TISCHFIELD JA, KING RA, ANDREWS AM, RAMAMOORTHY S, MCMAHON FJ, MURPHY DL: Common and rare alleles of the serotonin transporter gene, SLC6A4, associated with Tourette's disorder. Mov Disord 28: 1263-1270, 2013. https://doi.org/10.1002/mds. 25460

NAKAMURA M, UENO S, SANO A, TANABE H: The human serotonin transporter gene linked polymorphism (5-HTTLPR) shows ten novel allelic variants. Mol Psychiatry 5: 32-38, 2000. https://doi.org/10.1038/sj.mp.4000698

PITTENGER C, ADAMS TG, GALLEZOT JD, CROWLEY MJ, NABULSI N, JAMES R, GAO H, KICHUK SA, SIMPSON R, BILLINGSLEA E, HANNESTAD J, BLOCH M, MAYES L, BHAGWAGAR Z, CARSON RE: OCD is associated with an altered association between sensorimotor gating and cortical and subcortical 5-HT1b receptor binding. J Affect Disord 196: 87-96, 2016. https://doi.org/10.1016/j.jad.2016.02.021

QUEDNOW BB, ETTINGER U, MÖSSNER R, RUJESCU D, GIEGLING I, COLLIER D A, SCHMECHTIG A, KÜHN K-U, MÖLLER H-J, MAIER W, WAGNER M, KUMARI V: The schizophrenia risk allele C of the TCF4 rs9960767 polymorphism disrupts sensorimotor gating in schizophrenia spectrum and healthy volunteers. J Neurosci 31: 6684-6691, 2011. https://doi.org/10.1523/JNEUROSCI.0526-11.2011

QUEDNOW BB, GEYER MA, HALBERSTADT AL: Serotonin and schizophrenia. Handb Behav Neurosci 31: 711-743, 2020. https://doi.org/10.1016/B978-0-444-64125-0.00039-6

QUEDNOW BB, KOMETER M, GEYER MA, VOLLENWEIDER FX: Psilocybin-induced deficits in automatic and controlled inhibition are attenuated by ketanserin in healthy human volunteers. Neuropsychopharmacology 37 : 630-640, 2012. https://doi.org/10.1038/npp.2011.228

RAYMOND JR, MUKHIN YV, GELASCO A, TURNER J, COLLINSWORTH G, GETTYS TW, GREWAL JS, GARNOVSKAYA MN: Multiplicity of mechanisms of serotonin receptor signal transduction. Pharmacol Ther 92: 179-212, 2001. https://doi.org/10.1016/S0163-7258(01)00169-3 
ROVNÝ R, BESTERCIOVÁ D, RIEČANSKÝ I: Genetic determinants of gating functions: Do we get closer to understanding schizophrenia etiopathogenesis? Front Psychiatry 11: 550225, 2020. https://doi.org/10.3389/fpsyt.2020.550225

ROVNÝ R, MARKO M, KATINA S, MURÍNOVÁ J, ROHÁRIKOVÁ V, CIMROVÁ B, REPISKÁ G, MINÁRIK G, RIEČANSKÝ I: Association between genetic variability of neuronal nitric oxide synthase and sensorimotor gating in humans. Nitric Oxide 80: 32-36, 2018. https://doi.org/10.1016/J.NIOX.2018.08.002

SERRETTI A, CALATI R, MANDELLI L, DE RONCHI D: Serotonin transporter gene variants and behavior: A comprehensive review. Curr Drug Targets 2006. https://doi.org/10.2174/138945006779025419

SIPES TA, GEYER MA: Multiple serotonin receptor subtypes modulate prepulse inhibition of the startle response in rats. Neuropharmacology 33: 441-448, 1994. https://doi.org/10.1016/0028-3908(94)90074-4

SPIES M, KNUDSEN GM, LANZENBERGER R, KASPER S: The serotonin transporter in psychiatric disorders: Insights from PET imaging. Lancet Psychiatry 2: 743-755, 2015. https://doi.org/10.1016/S2215-0366(15)00232-1

SWERDLOW NR, AUERBACH P, MONROE SM, HARTSTON H, GEYER MA, BRAFF DL: Men are more inhibited than women by weak prepulses. Biol Psychiatry 34: 253-260, 1993. https://doi.org/10.1016/0006-3223(93)90079-S

SWERDLOW NR, LIGHT GA: Sensorimotor gating deficits in schizophrenia: Advancing our understanding of the phenotype, its neural circuitry and genetic substrates. Schizophr Res 198: 1-5, 2018. https://doi.org/10.1016/j.schres.2018.02.042

TAYLOR S: Molecular genetics of obsessive-compulsive disorder: A comprehensive meta-analysis of genetic association studies. Mol Psychiatry 18: 799-805, 2013. https://doi.org/10.1038/mp.2012.76

TOPALOGLU M, TUZUN E, GULEC H, BIRELLER ES, CAKMAKOGLU B, KUCUKALI CI: Neuronal nitric oxide synthase polymorphisms in obsessive-compulsive disorder. Nord J Psychiatry 71: 115-119, 2017. https://doi.org/10.1080/08039488.2016.1240230

TRIPATHI MK, KARTAWY M, AMAL H: The role of nitric oxide in brain disorders: Autism spectrum disorder and other psychiatric, neurological, and neurodegenerative disorders. Redox Biol 34: 101567, 2020. https://doi.org/10.1016/j.redox.2020.101567

VRANKOVA S, GALANDAKOVA Z, BENKO J, CEBOVA M, RIECANSKY I, PECHANOVA O: Duration of social isolation affects production of nitric oxide in the rat brain. Int J Mol Sci 22: 10340, 2021. https://doi.org/10.3390/ijms221910340

WILCOX R: A foundation for robust methods. In: Introduction to Robust Estimation and Hypothesis Testing. WILCOX R (ed.), Elsevier, Boston, 2012, pp 23-42. https://doi.org/10.1016/B978-0-12-386983-8.00002-0 